\title{
Effectiveness of motorcycle protective clothing: Riders' health outcomes in the six months following a crash
}

\author{
L. de Rome ${ }^{\mathrm{a}, *}$, R. Ivers ${ }^{\mathrm{a}}$, M. Fitzharris ${ }^{\mathrm{c}}$, N. Haworth ${ }^{\mathrm{d}}$, S. Heritier ${ }^{\mathrm{a}}$, D. Richardson ${ }^{\mathrm{b}}$ \\ ${ }^{a}$ The George Institute for Global Health, The University of Sydney, Australia \\ ${ }^{\mathrm{b}}$ Medical School, Australian National University, Australia \\ ${ }^{\mathrm{c}}$ Accident Research Centre, Monash Injury Research Institute, Monash University, Australia \\ ${ }^{\mathrm{d}}$ CARRS-Q (Centre for Accident Research and Road Safety - Queensland), Queensland University of Technology, Australia
}

\section{A R T I C L E I N F O}

\section{Article history:}

Accepted 22 October 2011

\section{Keywords:}

Motorcycle

Injury

Disability

Protective clothing

Injury prevention

Post-crash

Non-fatal crashes

Road crash injury

Return to work

\begin{abstract}
A B S T R A C T
Background: Little is known about the contribution of protective clothing worn in motorcycle crashes to subsequent health-related outcomes, impairment and quality of life.

Methods: A prospective cohort of 212 adult motorcyclists were recruited following presentations to hospitals or crash repair services in a defined geographic area in Australia between June 2008 and July 2009. Data was obtained from participant interviews and medical records at baseline, then by mailed survey two and six months post-crash $(n=146,69 \%)$. The exposure factor was usage of protective clothing classified as full protection (motorcycle jacket and pants), partial protection (motorcycle jacket) and unprotected (neither). Outcomes of interest included general health status (Short Form SF-36), disability (Health Assessment Questionnaire) treatment and recovery progress, quality of life and return to work in the six months post-crash.

Odds ratios (OR) were estimated for categorical outcomes using multiple logistic regression to assess differences in outcomes associated with levels of protection adjusted for potential confounders including age, sex, occupation, speed and type of impact. Non-parametric procedures were used for data that was not normally distributed.

Results: Compared to unprotected riders, both fully and partially protected riders had fewer days in hospital and reported less pain immediately post-crash; at two months both protection groups were less likely to have disabilities or reductions in physical function. By six months there were no significant differences in disability or physical function between groups, but both protection groups were more likely to be fully recovered and returned to pre-crash work than unprotected riders. Fully protected riders achieved better outcomes than either partially or unprotected riders on most measures. There were few significant differences between the full and partial protection groups although the latter showed greater impairment in physical health two months post-crash.

Conclusions: We found strong associations between use of protective clothing and mitigation of the consequences of injury in terms of post-crash health and well-being. Given this evidence it seems likely that the use of protective clothing will confer significant benefits to riders in the event of a crash.
\end{abstract}

(c) 2011 Elsevier Ltd. All rights reserved.

\section{Introduction}

Road traffic crashes are recognised as a major public health challenge and are predicted to become the third most common cause of disability worldwide by $2020 .^{1,2}$ As survival rates improve, particularly in high income countries, increasing attention is being

\footnotetext{
* Corresponding author at: Injury Division, The George Institute for Global Health, PO Box M201, Missenden Road, Sydney, NSW 2050, Australia. Tel.: +6129657 0361; fax: +61296570301.

E-mail addresses: lderome@georgeinstitute.org.au, liz@lderconsulting.com.au (L. de Rome).
}

paid to the high rates of impairment and disability associated with non-fatal injuries. ${ }^{3}$ Motorcyclists represent a significant proportion of road traffic casualties globally ${ }^{4}$ and are seen to be over represented in crashes in high income countries ${ }^{5,6}$ and amongst road casualties with high levels of disability. ${ }^{7-9}$ The need to design and evaluate countermeasures for motorcyclists is clear.

Whilst the benefits of motorcycle helmets in reducing head injury and death are well documented, ${ }^{10}$ other forms of motorcycle protective clothing have not been regarded as a significant safety measure for riders, largely because they have been assumed to have minimal effect in preventing serious injuries. ${ }^{11,12}$ Whilst there are limits to the extent that clothing can prevent injury in a high impact crash, it is in low impact crashes that protective 
clothing is thought to offer the greatest injury reduction. ${ }^{13}$ There is also evidence that many motorcycle crashes do not involve high impacts and a substantial proportion of riders sustain only relatively minor injuries in crashes. ${ }^{11,14}$

Such assumptions are also contrary to the evidence of a number of early studies, which documented significant injury reductions associated with use of motorcycle clothing. ${ }^{15-18}$ Indeed, Schuller reported that injured riders, who had worn protective clothing, returned to work sooner and were less likely to have permanent physical defects two years after the crash, compared to unprotected riders. ${ }^{19}$ The evidence generated by these early studies inspired research into the mechanics of protective clothing for motorcyclists, leading to the development of standards for motorcycle personal protective equipment (PPE) in Europe. ${ }^{20}$ This in turn has led to new technologies and the development of a new generation of protective clothing products. However to date the effectiveness of these products in reducing crash injuries has yet to be established.

'The Gear Study' aimed to examine the association between use of motorcycle protective clothing and injury, subsequent impairment and disability in a sample of crashed riders. The results of the first stage, documented elsewhere, demonstrated a significant protective effect on injury for riders wearing motorcycle clothing and particularly, when clothing was fitted with body armour. ${ }^{21}$ This paper aims to describe associations between use of protective clothing and subsequent impairment and disability.

\section{Method}

The Gear Study was a 12-month prospective cohort study of motorcyclists who crashed in the Australian Capital Territory between June 2008 and June 2009. Eligible motorcyclists included riders and passengers aged 17-70 years who were residents of the study area and involved in road crashes causing injury or motorcycle damage. Participants were volunteers recruited through the two hospitals and 13 motorcycle repair service in the study area. Motorcyclists were excluded if they had scored $<13$ on the Glasgow Coma Scale (GCS) or sustained severe head (AIS 3+) or spinal injuries, (AIS 4+) on the Abbreviated Injury Scale (AIS), ${ }^{22,23}$ or were otherwise unable to provide informed consent.

Baseline interviews were conducted face-face in participants' homes or in hospital approximately two weeks after their crash. Follow-up surveys were conducted by mail approximately two months and six months later. At baseline, participants completed questionnaires about their general health and functional ability prior to the crash. These were repeated in the follow-up surveys to monitor the longer term consequences of the crash with the reference period being the time since the crash, or 'over the past four weeks'.

At the baseline interview, information was collected about the crash, clothing worn, injury details and basic demographics. Details of the baseline study have been reported elsewhere. ${ }^{21}$ Injury reports were completed at the interview and corroborated with hospital records for independent scoring on the AIS scale by a trained assessor.

The current paper is an analysis of the two and six month follow-up data comparing riders' levels of protection with their recovery progress. The main exposure was usage of motorcycle protective clothing defined as clothing designed to provide protection from injury in motorcycle crashes. Motorcycle clothing designed for other purposes (e.g. wet weather protection) was not classified as protective. Three levels of protection were defined: Full - helmet, motorcycle jacket and motorcycle pants, Partial helmet and motorcycle jacket but non-motorcycle pants, Unprotected - helmet but no motorcycle jacket or pants. Riders without helmets were excluded from this analysis. Gloves and boots were not counted when assigning levels of protection.

The main outcomes were: days hospitalised; injury severity; self reported treatment and recovery progress; quality of life and return to work and residual pain. The Short Form Health Survey (SF-36, Version 1), ${ }^{24}$ and the Functional Disability Index (FDI) from the Health Assessment Questionnaire - Disability Index (HAQDI ${ }^{25}$ were also used.

Data on days hospitalised and injury severity were obtained from medical records. Questions on treatment, recovery progress, quality of life and return to work were adapted from previous studies. ${ }^{26}$

Injury severity was assessed using the Abbreviated Injury Scale (AIS) on which severity is classified from 1 (minor) to 6 (maximum). ${ }^{23}$ The Injury Severity Scores (ISS) is the sum of the squares of the highest AIS scores from three body regions. The MAIS (Maximum AIS) is the highest AIS code in cases of multiple injuries. MAIS scores were grouped into 4 levels: No injury, AIS 1 (minor), AIS 2 (Moderate) and AIS 3+ (serious to maximum).

Pain was measured on a horizontal Visual Analogue Scale (VAS) using a scale of $0=$ no pain to $151 \mathrm{~mm}=$ pain as bad as it could. ${ }^{27}$

The FDI assesses a comprehensive set of functional activities dressing, rising, eating, walking, hygiene, reach, grip and usual activities over the past week. Items are scored to indicate increasing degrees of disability from $0=$ without any difficulty to 3 = unable to do. The highest scores from each category are averaged to determine the disability index score and categorised into 4 levels of functional disability - (1) fully self-sufficient, (2) reasonably self-sufficient, (3) many difficulties but self-sufficient and (4) severely handicapped. For the regression analysis, these categories were combined to create a binary variable due to sample size restrictions. These were: (1) fully or reasonably self sufficient and (2) many difficulties or severely handicapped.

The SF-36 assesses general health over the past four weeks on 8 health domains, comprising 4 physical health components (Physical function, Role-physical, Bodily pain, General health) and 4 mental health components. ${ }^{24}$ (Vitality, Social function, Roleemotion and Mental health). Scores are expressed on a scale of 0 100. Summary scores are also calculated for the physical health (PCS) and mental health components (MCS). Difference scores on each health measure were calculated for each individual to measure change between baseline and two or six months and between two and six months.

Possible confounders of injury identified from the literature included age, ${ }^{8}$ gender, ${ }^{26}$ occupation ${ }^{28}$ and factors associated with the crash including type and estimated speed of impact. ${ }^{29-31}$ Age was categorised: $17-25,26-39$ and $40+$ years, which are identified as motorcycle crash risk age groups. ${ }^{32}$ Occupations were classified into four groups $(0=$ Not in workforce, $1=$ Manager/Administration/Professional, $2=$ Clerical/Sales/Services, $3=$ Trades/Labour). ${ }^{33}$ Injury causing impacts were classified into 4 types: No direct impact to body, slid on road only and impact with other vehicle or fixed object. Speed of impact was categorised into: 0-20, 21-40, $41-60$ and $>61 \mathrm{~km} / \mathrm{h}$.

Additional factors included motorcycle type: scooter, standard, touring, cruiser, supersport/sport and off-road; motorcycle engine displacement: $\quad<250, \quad 251-500, \quad 501-750, \quad 751-1000$ and $>1001 \mathrm{~cm}^{3}$; and riding experience: $<3$ years = novice.

Ethical approval was obtained from the Human Research Ethics Committees (HREC) for ACT Health and Calvary Health Care, and ratified by the University of Sydney.

\section{Data analysis}

The distribution of the general health measures including pain severity, time in hospital and off-work, and SF-36 scores were skewed with many outliers. Attempts to transform these scores to 
produce normal distributions were not successful. Significance tests based on assumptions of normality were therefore inappropriate so non-parametric tests were used.

Due to the presence of outliers, the Sign Test was used to examine differences in scores over time for the whole sample. The Wilcoxon rank sum test was used to examine between-group differences in planned comparisons of scores between baseline, two and six months. As these non-parametric procedures do not allow for the contribution of other factors, demographic and crash characteristics were examined separately using Chi-square tests to identify any systematic bias between exposure groups in the follow-up sample or the baseline cohort. The Chi-square test was used for categorical data, the Mantel-Haenszel chi-square for ordinal data and Fisher's exact test when cells contained small numbers.

Odds ratios and corresponding 95\% confidence intervals were computed for categorical factors relating to quality of life and return to work outcomes using the Logistic Regression procedure. Separate multivariable models were constructed for each outcome with initial screening rejecting any potential confounding variables with Chi-square $p>0.20$, then manual backwards elimination of those which contributed less than $5 \%$ to the estimate of effect.

\section{Results}

During the 12-month study period, 298 motorcyclists were identified as eligible for the study. Of those eligible $71.1 \%(n=212)$ participated, $19.8 \%(n=59)$ were not contactable, $8.1 \%(n=24)$ declined and $1.0 \%(n=3)$ were excluded on medical criteria.

The two-month and six-month surveys were returned by 148 participants (70\%), with the median period between their crash date and return of surveys being 62.5 days and 189 days respectively.

Two participants who were un-helmeted were excluded to avoid confounding injury outcomes. The remaining 146 motorcyclists when compared to those lost to follow-up $(n=66)$, included a smaller proportion of unprotected riders (13.0\% vs $28.8 \%$ ), more partially protected riders ( $54.8 \%$ vs $36.4 \%$ ) but similar proportions of fully protected riders (32.2\% vs $34.8 \%$ ). Overall categories these differences were significant $\left(\chi^{2}=9.26, p=0.01\right)$. There were also significant overall differences in age distribution $\left(\chi^{2}=4.10, p=0.04\right)$ with fewer young riders aged $17-25$ (24.7\% vs $39.4 \%)$ in the followup group and more of those aged $26-39$ (44.5\% vs $37.9 \%)$ and $40+$ years (30.8\% vs $22.7 \%$ ). There were no other significant differences in either demographic features (sex, employment status, occupational classification, income) or crash factors (crash type, impact speed or type of impact to the body) between those that completed and returned both follow-up surveys and those that did not.

\section{Baseline characteristics, the nature of protection and crash characteristics}

Table 1 compares exposure groups on clothing worn and on the crash characteristics identified as potential confounders of injury

Table 1

Age group, clothing worn and crash features by level of protection worn.

\begin{tabular}{|c|c|c|c|c|}
\hline & \multicolumn{4}{|c|}{ Level of protection worn } \\
\hline & Unprotected & Partial & Full & Total \\
\hline & $\%(n=19)$ & $\%(n=80)$ & $\%(n=47)$ & $\%(n=146)$ \\
\hline Age group & & & & $p=0.71^{\mathrm{a}}$ \\
\hline $17-25$ & 21.1 & 26.3 & 23.4 & 24.7 \\
\hline $26-39$ & 36.8 & 42.5 & 51.1 & 44.5 \\
\hline $40-75$ & 42.1 & 31.3 & 25.5 & 30.8 \\
\hline Type of crash & & & & $p=0.04^{\mathrm{b}}$ \\
\hline Single vehicle & 42.1 & 41.3 & 63.8 & 48.6 \\
\hline Multi-vehicle & 57.9 & 58.8 & 36.2 & 51.4 \\
\hline Impact speed & & & & $p=0.52^{\mathrm{a}}$ \\
\hline Under $20 \mathrm{~km} / \mathrm{h}$ & 21.1 & 27.5 & 29.8 & 27.4 \\
\hline $20-40 \mathrm{~km} / \mathrm{h}$ & 31.6 & 36.3 & 19.1 & 30.1 \\
\hline $41-60 \mathrm{~km} / \mathrm{h}$ & 26.3 & 18.8 & 21.3 & 20.5 \\
\hline $61+\mathrm{km} / \mathrm{h}$ & 10.5 & 12.5 & 17.0 & 13.7 \\
\hline Unknown & 10.5 & 5.0 & 12.8 & 8.2 \\
\hline \multicolumn{5}{|l|}{ Impact causing injury $^{\mathrm{c}}$} \\
\hline Impact to the body & 63.2 & 82.5 & 83.0 & $80.1^{\mathrm{ns}}$ \\
\hline Impact with other vehicle & 26.3 & 20.0 & 6.4 & $16.4(p=0.04)^{\mathrm{a}}$ \\
\hline Impact with fixed object & 15.8 & 12.5 & 14.9 & $13.7^{\text {ns }}$ \\
\hline Slid on road without other impact & 68.4 & 75.0 & 55.3 & $67.8^{\mathrm{ns}}$ \\
\hline \multicolumn{5}{|l|}{ Upper body protection } \\
\hline No motorcycle jacket & 100.0 & - & - & 13.0 \\
\hline Motorcycle jacket (no body armour) & - & 17.5 & 4.3 & 11.0 \\
\hline Motorcycle jacket with body armour & - & 82.5 & 95.7 & 76.0 \\
\hline \multicolumn{5}{|l|}{ Lower body protection } \\
\hline No motorcycle pants & 89.5 & 100.0 & - & 66.4 \\
\hline Motorcycle pants (no body armour) & 10.5 & - & 66.0 & 22.6 \\
\hline Motorcycle pants with body armour & - & - & 34.0 & 11.0 \\
\hline \multicolumn{5}{|l|}{ Hand and wrist protection } \\
\hline No gloves & 36.8 & 12.5 & - & 11.6 \\
\hline Motorcycle gloves (no body armour) & 36.8 & 38.8 & 40.4 & 39.0 \\
\hline Motorcycle gloves with body armour & 26.3 & 48.8 & 59.6 & 49.3 \\
\hline Foot and ankle protection & & & & $p=0.001^{\mathrm{a}}$ \\
\hline Shoes/joggers & 42.1 & 43.8 & 23.4 & 37.0 \\
\hline Non-motorcycle boots & 26.3 & 33.8 & 17.0 & 27.4 \\
\hline Motorcycle boots (no body armour) & 15.8 & 2.5 & 12.8 & 7.5 \\
\hline Motorcycle boots with body armour & 15.8 & 20.0 & 46.8 & 28.1 \\
\hline
\end{tabular}

NS, not significant.

a Fisher's exact test.

b Chi-square.

c Impacts causing injury are four separate factors and do not add up to $100 \%$ as multiple impacts could be recorded for each rider. 
Table 2

Baseline injury characteristics by level of protection worn.

\begin{tabular}{|c|c|c|c|c|}
\hline & \multicolumn{4}{|c|}{ Level of protection worn } \\
\hline & Unprotected & Partial & Full & Total \\
\hline & $\%(n=19)$ & $\%(n=80)$ & $\%(n=47)$ & $\%(n=146)$ \\
\hline Medical treatment required & & & & $p=0.04^{\mathrm{a}}$ \\
\hline No treatment & 10.5 & 16.3 & 17.0 & 15.8 \\
\hline General practitioner & 5.3 & 13.8 & 19.1 & 14.4 \\
\hline Emergency Department & 42.1 & 48.8 & 51.1 & 48.6 \\
\hline Admitted to hospital & 42.1 & 21.3 & 12.8 & 21.2 \\
\hline Maximum Injury Severity (MAIS) & & & & $p=0.61^{\mathrm{b}}$ \\
\hline No injury & 0.0 & 1.3 & 2.1 & 1.4 \\
\hline MAIS 1 (minor) & 63.2 & 72.5 & 76.6 & 72.6 \\
\hline MAIS 2 (moderate) & 26.3 & 17.5 & 19.1 & 19.2 \\
\hline MAIS 3-6 (serious, severe, critical) & 10.5 & 8.8 & 2.1 & 6.8 \\
\hline Injury Severity Score (ISS) & & & & $p=0.45^{\mathrm{d}}$ \\
\hline Mean (Standard deviation) & $5.3(6.1)$ & $3.9(3.3)$ & $3.9(4.0)$ & $4.1(4.0)$ \\
\hline Median (inter-quartile range) & $3.0(3.0)$ & $3.0(3.0)$ & $3.0(1.0)$ & $3.0(3.0)$ \\
\hline \multicolumn{5}{|l|}{ Types of injury - cuts/abrasions } \\
\hline Head & 5.3 & $6.3^{\text {ns }}$ & $6.4^{\mathrm{ns}}$ & 6.2 \\
\hline Upper torso & 0.0 & 0.0 & 0.0 & 0.0 \\
\hline Arms/shoulders & 57.9 & $26.3(p=0.01)^{\mathrm{c}}$ & $23.4(p=0.01)^{\mathrm{C}}$ & $29.5(p=0.01)^{\mathrm{c}}$ \\
\hline Hands & 31.6 & 22.5 & $12.8(p=0.07)^{c}$ & 20.5 \\
\hline Lower torso & 10.5 & 6.3 & 4.3 & 6.2 \\
\hline Legs & 52.6 & 55.0 & $29.8(p=0.08)^{\mathrm{c}}$ & $46.6(p=0.02)^{c}$ \\
\hline Feet & 10.5 & 15.0 & 10.6 & 13.0 \\
\hline \multicolumn{5}{|l|}{ Types of injury - fractures } \\
\hline Head & 0.0 & 1.3 & 0.0 & 0.7 \\
\hline Upper torso & 5.3 & 5.0 & 6.4 & 5.5 \\
\hline Arms/shoulders & 31.6 & $12.5(p=0.04)^{\mathrm{c}}$ & $12.8(p=0.07)^{\mathrm{c}}$ & $15.1(p=0.09)$ \\
\hline Hands & 5.3 & 11.3 & 8.5 & 9.6 \\
\hline Lower torso & 0.0 & 0.0 & 2.1 & 0.7 \\
\hline Legs & 5.3 & 0.0 & 2.1 & 1.4 \\
\hline Feet & 0.0 & 7.5 & 12.8 & 8.2 \\
\hline Any upper body fractures & 31.6 & 16.3 & 14.9 & 17.8 \\
\hline Any lower body fractures & 5.3 & 2.5 & 8.5 & 4.8 \\
\hline $\begin{array}{l}\text { NS, Not significant. } \\
\text { a Mantel-Haenszel chi-square. } \\
\text { b Fisher's exact test. } \\
\text { c Chi-square. } \\
\text { d Kruskal-Wallis test. }\end{array}$ & & & & \\
\hline
\end{tabular}

severity. Those wearing full protection had been involved in a higher proportion of single than multi-vehicle crash $(\chi=6.4$, $p=0.04$ ) and were less likely to have injuries from an impact with another vehicle (Fisher's exact test, $p=0.04$ ). There were no other significant differences on these demographic and crash characteristics between protection levels. There were no significant associations between protection levels and type or size of motorcycle nor riding experience.

Over one-third of the unprotected group rode without gloves (36.8\%) and $42.1 \%$ were wearing shoes or joggers. A high proportion $(82.5 \%)$ of the partial protection group had impact protectors fitted in their jackets, most wore motorcycle gloves ( $87.6 \%$ ) but only $22.5 \%$ wore motorcycle boots and $43.8 \%$ wore shoes or joggers. The full protection group all wore motorcycle gloves (100\%) and a high proportion wore motorcycle boots (59.6\%) and they were more likely than either of the other groups to be wearing body armour.

\section{Injuries sustained, by protection group}

Table 2 compares injury characteristics at baseline by level of protection. The partial and full protection groups were less likely than unprotected riders to have attended or been admitted to hospital $(p=0.04)$; to sustain arm or shoulder cuts/abrasion $(p=0.01)$ or fractures (partial: $p=0.04$; full: $p=0.07$ ). Those with full protection were less likely to have leg cuts/abrasions than the partial $(p=0.01)$ or unprotected $(p=0.08)$ groups. There were no other significant differences in injuries or injury severity between groups. Whereas $72.6 \%(n=106)$ overall were assessed as having relatively minor injuries (MAIS 1 ), these were not necessarily trivial injuries. Whilst most were not technically admitted to hospital, almost half of these riders (48.1\%) spent at least one day in hospital, five of whom were admitted for up to three days. A further $19.2 \%(n=28)$ sustained moderate injuries (MAIS 2) and $6.8 \%$ $(n=10)$ were assessed as serious to severe (MAIS 3-6).

\section{General health and return-to-work outcomes}

The combined groups reported significant reductions in pain severity at two months $(p<0.0001)$ and six months $(p<0.0001)$ post-crash compared to baseline levels. Table 3 presents the general health outcomes across those with different levels of protection. Increasing levels of protection was associated with fewer days in hospital $(p \leq 0.04)$ and lower levels of self-reported pain at baseline $(p \leq 0.01)$. A small proportion of motorcyclists in the full and partial protection group were pain free at baseline and notably none of the unprotected group, though these differences were not statistically significant. The proportion of riders who were pain free in each group had increased by twomonths. Further improvements in pain free status were observed only for the protected groups at six months.

Despite the significant differences reported at baseline, differences between groups in the severity of self-reported pain reported at two and six months were not significant. In addition, whilst unprotected riders appeared to have had more time off work (mean $=22.0$ days) compared to those with partial or full protection (mean $=13.8$ and 9.5 days respectively), the differences were not statistically significant. 
Table 3

Pain, days incapacitated and health outcomes associated with level of protectiona.

\begin{tabular}{|c|c|c|c|c|}
\hline & \multicolumn{4}{|c|}{ Level of protection worn } \\
\hline & Unprotected $(n=19)$ & Partial $(n=80)$ & Full $(n=47)$ & All levels $(n=146)$ \\
\hline \multicolumn{2}{|l|}{ Days in hospital } & $p=0.04^{\mathrm{a}}$ & $p=0.01^{\mathrm{a}}$ & $p=0.03^{d}$ \\
\hline Mean (SD) & $3.5(9.0)$ & $2.6(14.1)$ & $0.7(1.1)$ & $2.1(11.0)$ \\
\hline Median (inter-quartile range) & $1.0(1.0-3.0)$ & $1.0(0.0-1.0)$ & $0.0(0.0-1.0)$ & $1.0(0.0-1.0)$ \\
\hline \multicolumn{2}{|l|}{ Most severe pain at baseline } & $p=0.01^{\mathrm{a}}$ & $p=0.001^{\mathrm{a}}$ & $p=0.01^{\mathrm{d}}$ \\
\hline Mean (SD) & $116.7(37.5)$ & $92.4(41.0)$ & $85.3(39.6)$ & 9.3. $(41.0)$ \\
\hline Median (inter-quartile range) & $121.0(102.0-151.0)$ & $106.0(67.0-121.0)$ & $91.0(62.0-115.0)$ & $106.0(68.0-121.0)$ \\
\hline$\%$ zero pain & & 3.8 & 4.3 & $3.4(p=1.0)^{\mathrm{c}}$ \\
\hline \multicolumn{2}{|l|}{ Most severe pain at two months } & $p=0.40^{\mathrm{a}}$ & $p=0.60^{\mathrm{a}}$ & $p=0.06^{\mathrm{d}}$ \\
\hline Mean (SD) & $36.1(38.6)$ & $41.7(40.7)$ & $26.4(34.2)$ & $36.0(38.8)$ \\
\hline Median (inter-quartile range) & $19.0(0.0-75.5)$ & $30.6(7.0-60.0)$ & $15.1(0.0-38.0)$ & $25.0(0.0-56.0)$ \\
\hline$\%$ zero pain & 36.8 & 17.5 & 36.2 & $26.0(p=0.04)^{c}$ \\
\hline \multicolumn{2}{|l|}{ Most severe pain at six months } & $p=0.61^{\mathrm{a}}$ & $p=0.41^{\mathrm{a}}$ & $p=0.70^{\mathrm{d}}$ \\
\hline Mean (SD) & $25.3(30.8)$ & $24.8(34.2)$ & $21.2(30.6)$ & $23.7(32.5)$ \\
\hline Median (inter-quartile range) & $7.5(0.0-45.0)$ & $12.5(0.0-30.0)$ & $5.0(0.0-30.0)$ & $7.8(0.0-31.0)$ \\
\hline$\%$ zero pain & 36.8 & 43.8 & 48.9 & $44.5(p=0.67)^{\mathrm{c}}$ \\
\hline \multicolumn{2}{|c|}{ Pain score reduction baseline - two months } & $p=0.01^{\mathrm{a}}$ & $p=0.09^{a}$ & $p<0.0001^{\mathrm{b}}$ \\
\hline Mean (SD) & $80.6(40.7)$ & $51.0(42.1)$ & $57.8(42.6)$ & $57.1(42.9)$ \\
\hline Median (inter-quartile range) & $84.0(45.5-118.0)$ & $49.4(15.1-84.0)$ & $67.5(19.0-91.0)$ & $60.7(20.0-90.7)$ \\
\hline \multicolumn{2}{|c|}{ Pain score reduction two - six months } & $p=0.07^{\mathrm{a}}$ & $p=0.04^{\mathrm{a}}$ & $p<0.0001^{\mathrm{b}}$ \\
\hline Mean (SD) & $10.8(45.6)$ & $19.2(34.2)$ & $4.7(34.1)$ & $13.3(36.1)$ \\
\hline Median (inter-quartile range) & $6.0(0.0-44.0)$ & $11.8(0.0-31.5)$ & $0.0(-7.0$ to 15.1$)$ & $8.0(0.0-30.4)$ \\
\hline \multicolumn{2}{|c|}{ Total days off work since crash six months } & $p=0.28^{\mathrm{a}}$ & $p=0.15^{\mathrm{a}}$ & \\
\hline Mean (SD) & $22.0(40.3)$ & $13.8(29.6)$ & $9.5(24.9)$ & $13.5(29.8)$ \\
\hline Median (inter-quartile range) & $7.0(0.0-14.0)$ & $2.0(0.0-15.0)$ & $3.0(0.0-10.0)$ & $3.0(0.0-13.0)$ \\
\hline \multicolumn{5}{|c|}{ SF-36 Physical Components Summary (PCS) } \\
\hline Baseline mean (SD) & $57.4(4.9)$ & $55.6(4.9)$ & $54.9(5.6)$ & $55.7(5.1)$ \\
\hline Two months mean (SD) & $43.5(12.8)$ & $46.0(10.2)$ & $47.5(11.8)(p=0.04)^{\mathrm{a}}$ & $46.2(11.1)(p=0.05)^{\mathrm{d}}$ \\
\hline Six months mean (SD) & $53.6(9.3)$ & $51.9(9.1)$ & $52.8(7.8)(p=0.62)^{a}$ & $52.4(8.7)$ \\
\hline Australian norm & & & & 49.8 \\
\hline \multicolumn{5}{|c|}{ SF-36 Mental Components Summary (MCS) } \\
\hline Baseline mean (SD) & $47.9(12.7)$ & $53.2(6.3)$ & $53.8(7.6)$ & $52.7(8.0)$ \\
\hline Two months mean (SD) & $49.2(12.3)$ & $51.4(8.6)$ & $50.8(8.7)(p=0.02)^{\mathrm{a}}$ & $50.9(9.1)(p=0.05)^{d}$ \\
\hline Six months mean (SD) & $47.9(13.1)$ & $52.0(7.5)$ & $51.6(9.4)(p=0.04)^{a}$ & $51.4(9.0)(p=0.01)^{d}$ \\
\hline Australian norm & & & & 50.8 \\
\hline
\end{tabular}

a Pllanned comparisons $p$ values from Wilcoxon rank sums test.

b Total scores over time $p$ values from sign test.

c Chi-square p value.

${ }^{\mathrm{d}}$ Between groups global $p$-values from Kruskal-Wallis Test.

Physical and mental health status on the SF-36 was examined in each of the protection groups. At two months, scores across groups on each SF-36 physical and mental health domain had declined significantly compared to their baseline. In percentage terms the greatest changes related to physical domains with mean scores reduced on role-physical $(38.8 \%, p<0.0001)$, bodily pain $(27.7 \%$, $p<0.0001)$, physical function $(14.5 \%, p<0.0001)$ and general health $(7.5 \%, p=0.02)$. On mental health domains the mean scores reduced on social function $(15.5 \%, p<0.0001)$, vitality $(14.5 \%$, $p<0.0001)$, role-emotion $(14.0 \%, p<0.0001)$ and mental health $(5 \%, p=0.01)$. Between two and six months, scores across groups improved with means on most domains coming within $7 \%$ of their baseline, with the exception of role-physical and bodily pain which remained $12.7 \%$ and $12.3 \%$ respectively below baseline.

Table 3 shows the differences across groups in the magnitude of change between baseline and two months on the SF-36 mental components summary (MCS: $p=0.05$ ) and physical components summary (PCS: $p=0.05$ ). At six months there was a significant difference only on MCS scores $(p=0.01)$.

When difference scores were calculated, unprotected riders scores showed greater reduction in the PCS score at two months than fully protected riders $(-13.9$ vs $-6.9, p=0.04)$, whilst both groups had improved by six months to show only a minimal remaining health loss $(-3.9$ vs $-2.1, p=0.62)$. On the MCS score, unprotected riders showed a slight improvement in mean MCS between baseline and two months, compared to a reduction for those with full protection (+1.3 vs $-2.9, p=0.02)$. At six months the unprotected riders mean score on MCS had declined, whereas the fully protected riders had improved $(-0.6$ vs $+2.3, p=0.04)$. There were no significant differences between unprotected and partially protected riders at either two or six months on PCS $(p=0.11$ and $p=0.83)$ and only marginal differences on MCS ( $p=0.06$ and $p=0.08)$.

There were differences between partially and fully protected riders at two months, with the partially protected showing a greater decline on PCS at two months $(-7.3 \%$ vs $-13.5, p=0.04)$ compared to fully protected riders. There were no significant differences between these groups on MCS at two months $(p=0.28)$ nor either MCS or PCS at six months $(p=0.39$ and $p=0.72)$.

Figs. 1 and 2 show group mean scores on the eight domains of the SF-36 at baseline two and six months compared to the Australian mean scores. ${ }^{34}$ At baseline, each groups' scores on the SF-36 domains were above Australian norms in the four weeks prior to the crash on all physical health domains ( $p<0.0001$; see Fig. 1). On the mental health domains, the two protected groups were also above the norms at baseline $(p<0.001)$, whereas the unprotected group were lower although not significantly different to the Australian norms (see Fig. 2).

At two months, the mean scores for unprotected riders on SF-36 physical function was $28.1 \%$ lower than their baseline, compared to partially $(11.5 \%, p=0.04)$ and fully protected riders $(13.9 \%$, $p=0.03$ ). Their mean scores on role-physical were $44.3 \%$ lower than baseline compared to the partially (35.0\%) and fully (27.8\%) protected riders but those differences were not significant. Nor were there any significant differences between groups in the magnitude of change in bodily pain or general health from baseline to two months. 


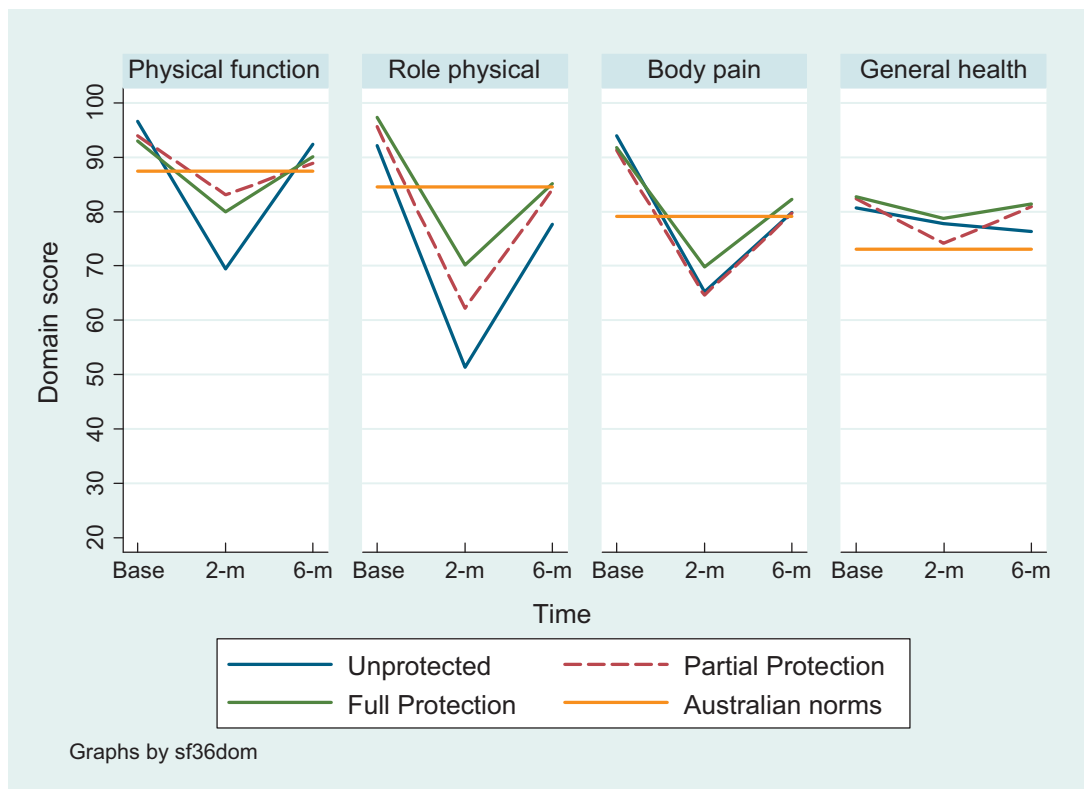

Fig. 1. Mean scores over time on SF-36 physical component domains by level of protection and compared to population norms.

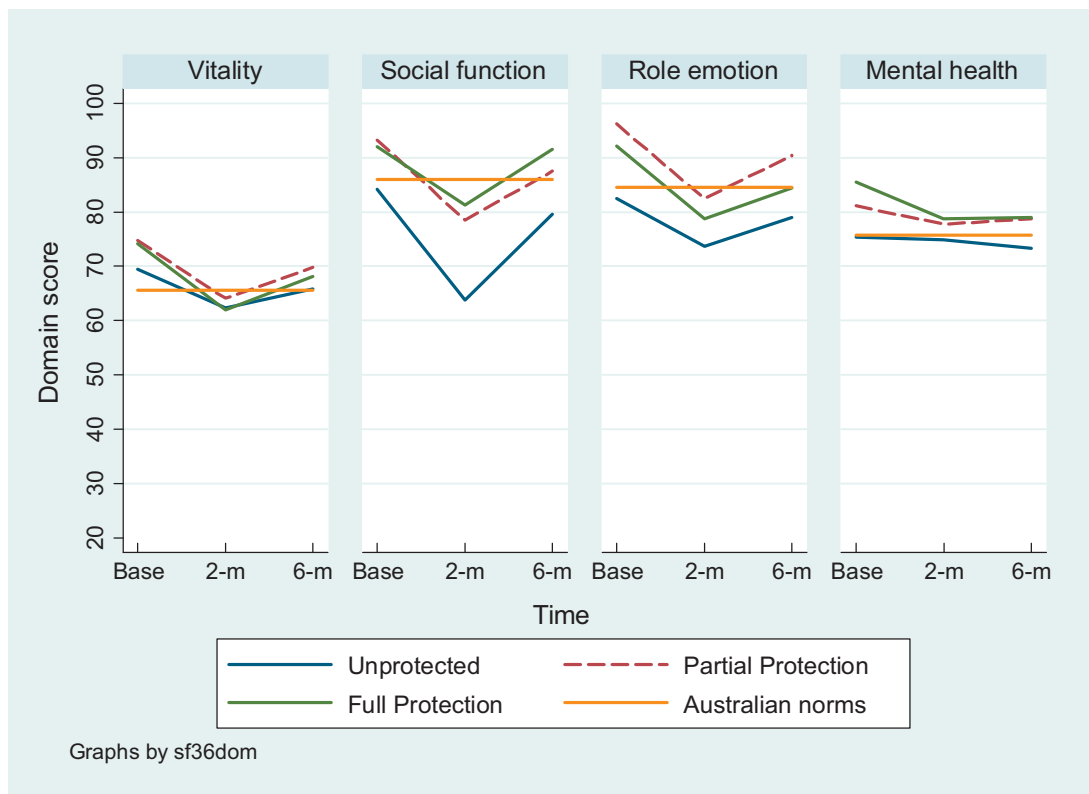

Fig. 2. Mean scores over time on SF-36 mental component domains by level of protection and compared to population norms.

On SF-36 mental health domains, unprotected riders had lower mean scores than either protected group on role-emotion and mental health at two months, but these differences were not significant, and nor was there any significant differences between groups in the magnitude of change since baseline. Unprotected riders' scores on social function were lower than partially ( mean $=63.8$ vs 78.5, $p=0.06$ ) or fully protected riders ( mean $=63.8$ vs $81.3, p=0.03$ ). However there were no significant differences in the magnitude of change between groups when difference scores on social function between baseline and two month were calculated.

Between two and six months unprotected riders' mean score on physical function improved $22.9 \%$ from baseline compared to the degree of improvement for partially $(5.8 \%, p=0.02)$ and fully protected riders $(10.1 \%, p=0.04)$. However the mean scores for general health amongst the unprotected riders was lower at six months in contrast to the percentage improvement seen in the partially protected group $(-1.8 \%$ vs $9.1 \%, p=0.06)$ and the fully protected group $(-1.8 \%$ vs $3.4 \%, p=17)$.

At six months, unprotected riders had lower mean scores than either protected groups on all mental health domains, but the only significant difference was with fully protected riders on social function (mean $=79.6$ vs 91.5, $p=0.04$ ). However there was no significant difference between groups in the magnitude of change when difference scores on social function between baseline and six months were calculated.

At six months partially protected riders were significantly closer to their baseline mental health scores than the fully protected riders $(2.9 \%$ vs $7.7 \%, p=0.03)$. There were no other significant differences between partially and fully protected riders on SF-36 domains at two or six months.

Across groups, self rating of general health on the SF-36 deteriorated significantly in the two months since baseline with 
Table 4

General health associated with level of protection.

\begin{tabular}{|c|c|c|c|c|c|c|c|c|c|c|}
\hline & \multicolumn{10}{|c|}{ Level of protection worn } \\
\hline & \multicolumn{3}{|c|}{ Unprotected \% $(n=19)$} & \multicolumn{3}{|c|}{ Partial \% $(n=80)$} & \multicolumn{3}{|c|}{ Full $\%(n=47)$} & \multirow{2}{*}{$\begin{array}{l}\text { Total }(n=146) \\
6 \text { months }\end{array}$} \\
\hline & Baseline & 2 months & 6 months & Baseline & 2 months & 6 months & Baseline & 2 months & 6 months & \\
\hline \multicolumn{11}{|c|}{ Self rated general health } \\
\hline Excellent & 47.4 & 21.1 & 31.6 & 41.3 & 21.3 & 42.5 & 46.8 & 23.4 & 40.4 & 40.4 \\
\hline Very good & 31.6 & 47.4 & 31.6 & 45.0 & 36.3 & 27.5 & 38.3 & 44.7 & 42.6 & 32.9 \\
\hline Good & 15.8 & 10.5 & 31.6 & 12.5 & 32.5 & 25.0 & 8.5 & 21.3 & 10.6 & 21.2 \\
\hline Fair & 5.3 & 15.8 & 5.3 & 1.3 & 7.5 & 3.8 & 6.4 & 8.5 & 4.3 & 4.1 \\
\hline Poor & 0.0 & 5.3 & 0.0 & 0.0 & 2.5 & 1.3 & 0.0 & 2.1 & 2.1 & 1.4 \\
\hline
\end{tabular}

Table 5

Functional disability associated with level of protection.

\begin{tabular}{|c|c|c|c|c|c|c|c|c|c|c|}
\hline & \multicolumn{10}{|c|}{ Level of protection worn } \\
\hline & \multicolumn{3}{|c|}{ Unprotected \% $(n=19)$} & \multicolumn{3}{|c|}{ Partial \% $(n=80)$} & \multicolumn{3}{|c|}{ Full \% $(n=47)$} & \multirow{2}{*}{$\begin{array}{l}\text { Total } \%(n=148) \\
6 \text { months }\end{array}$} \\
\hline & Baseline & 2 months & 6 months & Baseline & 2 months & 6 months & Baseline & 2 months & 6 months & \\
\hline \multicolumn{11}{|c|}{ Functional Disability Index (in past 7 days) ${ }^{a}$} \\
\hline None & 100.0 & 68.4 & 89.5 & 98.8 & 73.8 & 91.3 & 100.0 & 80.9 & 95.7 & 92.5 \\
\hline Mild & 0.0 & 10.5 & 5.3 & 1.2 & 21.3 & 6.3 & 0.0 & 14.9 & 2.1 & 4.8 \\
\hline Moderate & 0.0 & 5.3 & 5.3 & 0.0 & 2.5 & 1.3 & 0.0 & 2.1 & 2.1 & 2.1 \\
\hline Severe & 0.0 & 15.8 & 0.0 & 0.0 & 2.5 & 1.3 & 0.0 & 2.1 & 0.0 & 0.7 \\
\hline
\end{tabular}

${ }^{a}$ None - completely self-sufficient, Mild - reasonably self-sufficient, Moderate - self sufficient but many problems, Severe - severely handicapped.

the proportion rating themselves "excellent" or "very good" dropping from $84.9 \%$ to $62.3 \%(p<0.0001)$. At two months a higher proportion of unprotected riders rated their health as fair $(15.8 \%)$ or poor $(5.3 \%)$, compared to partially $(7.5 \%, 2.5 \%)$ or fully protected riders $(8.5 \%, 2.1 \%)$ respectively but these differences were not significant. By six months, health ratings had recovered almost to pre-crash levels (mean $=1.75$ vs $1.92, p=0.07$ ). Despite this improvement at six months, $26.7 \%$ of all riders still rated their health as less than very good or excellent compared to $15.1 \%$ at baseline (Table 4).

Table 5 shows the distribution of disability scores by level of protection.-Scores on the Functional Disability Index (FDI, HAQ-DI) show a higher proportion of unprotected riders at two months to be moderately (5.3\%) or severely handicapped (15.8\%) compared to those with partial (2.5\% and $2.5 \%$ ) and full $(2.1 \%$ and $2.1 \%$ ) protection. These differences were not significant nor were there any significant differences between any groups at baseline or six months.

Table 6 shows the proportions from each group who reported 'much difficulty' or being 'unable to perform' specific activities of daily living (ADLs) on the HAQ-DI. Unprotected riders were more likely to report difficulties with grip and normal daily activities than those with partial protection and with dressing, hygiene, reach and grip than those with full protection $(p \leq 0.05)$. The differences were not significant between the partial and full protection groups.

\section{Multivariate analysis of health outcomes by protection group}

Table 7 presents odds ratios (OR) for recovery, return to work and quality of life indicators, unadjusted and adjusted with the factors identified as significant though backwards elimination.

At two months, riders with partial protection were less likely than unprotected riders to report reduced quality of life (Adj. $\mathrm{OR}=0.25,95 \% \mathrm{CI}: 0.08-0.80)$ or to have moderate or severe disabilities (Adj. OR =0.12, 95\%CI: 0.02-0.80).

Those with full protection were less likely than unprotected riders to have been admitted to hospital (Adj. OR $=0.21$, 95\%Cl:0.06-0.73) or to have moderate or severe disabilities (Adj. $\mathrm{OR}=0.12,95 \% \mathrm{CI}$ : 0.02-0.95) at two months. They were also less likely to report reduced quality of life however the association was not significant when the potential confounders were controlled.

At six months, those with partial protection were more likely than unprotected riders to rate themselves as fully recovered

Table 6

Percentage reporting 'much difficulty' or 'unable to do' in performance of daily living activities (ADL) domain Functional Disability Index (HAQ-DI).

\begin{tabular}{|c|c|c|c|c|c|c|c|c|}
\hline \multirow[t]{3}{*}{ ADL domain } & \multicolumn{8}{|c|}{ Level of protection worn } \\
\hline & \multicolumn{2}{|c|}{ Unprotected \% } & \multicolumn{2}{|l|}{ Partial \% } & \multicolumn{2}{|l|}{ Full \% } & \multicolumn{2}{|l|}{ Total \% } \\
\hline & 2 months & 6 months & 2 months & 6 months & 2 months & 6 months & 2 months & 6 months \\
\hline Dressing & 21.1 & 0.0 & 7.5 & 5.0 & $2.1^{\mathrm{a}}$ & 2.1 & $7.5^{\mathrm{b}}$ & 3.4 \\
\hline Arising & 15.8 & 5.3 & 6.3 & 2.5 & 4.3 & 0.0 & 6.8 & 2.1 \\
\hline Eating & 21.1 & 0.0 & 7.5 & 1.3 & 10.6 & 2.1 & 10.3 & 1.4 \\
\hline Walking & 10.5 & 0.0 & 6.3 & 3.8 & 10.6 & 2.1 & 8.2 & 2.7 \\
\hline Hygiene & 21.1 & 5.3 & 7.5 & 5.0 & $4.3^{\mathrm{a}}$ & 2.1 & 8.2 & 4.1 \\
\hline Reach & 21.1 & 10.5 & 10.0 & 5.0 & $4.3^{\mathrm{a}}$ & 2.1 & 9.6 & 4.8 \\
\hline Grip & 26.3 & 0.0 & $8.8^{\mathrm{a}}$ & 2.5 & $4.3^{\mathrm{a}}$ & 2.1 & $9.6^{\mathrm{b}}$ & 2.1 \\
\hline Activities & 31.6 & 10.5 & $10.0^{\mathrm{a}}$ & 6.3 & 19.1 & 4.3 & $15.8^{\mathrm{b}}$ & 6.2 \\
\hline
\end{tabular}

a Significance $(p \leq 0.05)$. Fisher exact test - planned comparison with Unprotected group.

b Chi-square Test $(p \leq 0.05)$ - difference across groups. 
Table 7

Health and quality of life outcomes associated with level of protection.

\begin{tabular}{|c|c|c|c|c|c|c|c|c|}
\hline \multirow[t]{2}{*}{ Level of protection } & \multicolumn{2}{|c|}{ Health outcome } & \multirow[t]{2}{*}{ Unadjusted OR } & \multirow[t]{2}{*}{$95 \% \mathrm{CI}$} & \multirow[t]{2}{*}{$p$} & \multirow[t]{2}{*}{ Adjusted $\mathrm{OR}^{\mathrm{a}}$} & \multirow[t]{2}{*}{$95 \% \mathrm{CI}$} & \multirow[t]{2}{*}{$p$} \\
\hline & No $\%$ & Yes \% & & & & & & \\
\hline \multicolumn{6}{|l|}{ Admitted to hospital } & \multicolumn{3}{|c|}{ Adjusted for age and sex } \\
\hline Unprotected & & 57.9 & 42.1 & & & & & \\
\hline Partial protection & 78.8 & 21.3 & 0.37 & $0.13-1.07$ & 0.07 & 0.40 & $0.14-1.17$ & 0.09 \\
\hline Full protection & 87.2 & 12.8 & 0.20 & $0.06-0.70$ & 0.01 & 0.21 & $0.06-0.73$ & 0.01 \\
\hline \multicolumn{9}{|c|}{ Follow-up at two months } \\
\hline \multicolumn{6}{|c|}{ Treatment ongoing } & \multicolumn{3}{|c|}{ Adjusted for age and sex } \\
\hline Unprotected & & 33.3 & 66.7 & & & & & \\
\hline Partial protection & 55.3 & 44.7 & 0.41 & $0.14-1.19$ & 0.10 & 0.46 & $0.15-1.40$ & 0.17 \\
\hline Full protection & 57.8 & 42.2 & 0.37 & $0.12-1.15$ & 0.08 & 0.39 & $0.12-1.28$ & 0.12 \\
\hline \multicolumn{6}{|c|}{ Rates self as fully recovered } & \multicolumn{3}{|c|}{ Adjusted for age, sex and impact with a fixed object } \\
\hline Unprotected & & 77.8 & 22.2 & & & & & \\
\hline Partial protection & 67.9 & 32.1 & 1.65 & $0.49-5.53$ & 0.42 & 1.35 & $0.37-4.84$ & 0.65 \\
\hline Full protection & 59.6 & 40.4 & 2.38 & $0.68-8.33$ & 0.18 & 2.12 & $0.56-8.10$ & 0.27 \\
\hline \multicolumn{6}{|c|}{ Returned to pre-crash work role } & \multicolumn{3}{|c|}{ Adjusted for age and sex } \\
\hline Unprotected & & 20.0 & 80.0 & & & & & \\
\hline Partial protection & 14.5 & 85.5 & 1.48 & $0.35-6.17$ & 0.59 & 1.35 & $0.30-5.99$ & 0.69 \\
\hline Full protection & 5.0 & 95.0 & 4.75 & $0.71-31.86$ & 0.11 & 4.41 & $0.64-30.62$ & 0.13 \\
\hline \multicolumn{6}{|l|}{ Quality of life reduced } & \multicolumn{3}{|c|}{ Adjusted for age, sex, slide and impact speed $<40 \mathrm{~km} / \mathrm{h}$} \\
\hline \multicolumn{2}{|l|}{ Unprotected } & 36.8 & \multicolumn{3}{|l|}{63.2} & & & \\
\hline Partial protection & 67.1 & 32.9 & 0.29 & $0.10-0.81$ & 0.02 & 0.25 & $0.08-0.80$ & 0.02 \\
\hline Full protection & 65.2 & 34.8 & 0.31 & $0.10-0.95$ & 0.04 & 0.39 & $0.11-1.34$ & 0.13 \\
\hline \multicolumn{6}{|c|}{ Moderate/severe disability } & \multicolumn{3}{|c|}{ Adjusted for age, sex and type of impact } \\
\hline Unprotected & & 78.9 & 21.1 & & & & & \\
\hline Partial protection & 95.0 & 5.0 & 0.20 & $0.04-0.88$ & 0.03 & 0.12 & $0.02-0.80$ & 0.03 \\
\hline Full protection & 91.5 & 8.5 & 0.35 & $0.08-1.57$ & 0.17 & 0.12 & $0.02-0.95$ & 0.04 \\
\hline Follow-up at six mo & & & & & & & & \\
\hline Treatment ongoing & & & & & & $\begin{array}{l}\text { Adjusted for ag } \\
\text { body }\end{array}$ & and direct in & \\
\hline Unprotected & & 63.2 & 36.8 & & & & & \\
\hline Partial protection & 79.7 & 20.3 & 0.44 & $0.05-1.28$ & 0.13 & 0.44 & $0.13-1.49$ & 0.19 \\
\hline Full protection & 89.4 & 10.6 & 0.20 & $0.06-0.76$ & 0.02 & 0.13 & $0.03-0.59$ & 0.01 \\
\hline Rates self as fully rec & & & & & & Adjusted for $\mathrm{a}$ & sex & \\
\hline Unprotected & & 73.7 & 26.3 & & & & & \\
\hline Partial protection & 38.8 & 61.3 & 4.43 & $1.45-13.51$ & 0.01 & 4.69 & $1.32-16.63$ & 0.02 \\
\hline Full protection & 36.2 & 63.8 & 4.94 & $1.52-16.11$ & 0.01 & 6.22 & $1.60-24.15$ & 0.01 \\
\hline Returned to pre-crasl & $\mathrm{k}$ role & & & & & Adjusted for a & and occupat & bour \\
\hline Unprotected & & 42.1 & 57.9 & & & & & \\
\hline Partial protection & 10.1 & 89.9 & 6.46 & $2.01-20.75$ & 0.002 & 5.70 & $1.57-20.68$ & 0.01 \\
\hline Full protection & 6.5 & 93.5 & 10.42 & $2.37-45.93$ & 0.002 & 7.98 & $1.66-38.42$ & 0.01 \\
\hline Quality of life reduce & & & & & & Adjusted for a & sex & \\
\hline Unprotected & & 68.4 & 31.6 & & & & & \\
\hline Partial protection & 77.5 & 22.5 & 0.63 & $0.21-1.89$ & 0.41 & 0.79 & $0.24-2.58$ & 0.70 \\
\hline Full protection & 85.1 & 14.9 & 0.38 & $0.11-1.33$ & 0.13 & 0.40 & $0.11-1.52$ & 0.18 \\
\hline
\end{tabular}

a The base model included age, sex, occupation, impact type, speed of impact and type of impact (slide, fixed object). The final model for each outcome factor includes age and sex in addition to any other factors from the base model that contributed $5 \%$ or more to the effect.

(Adj. OR $=4.69,95 \% \mathrm{CI}: 1.32-16.63$ ) and to have returned to precrash work roles (Adj. OR $=5.70,95 \% \mathrm{CI}$ : $1.57-20.68$ ). The fully protected were less likely than unprotected riders to have treatment ongoing (Adj. OR=0.13, 95\%CI: 0.03-0.59) and more likely to rate themselves fully recovered (Adj. OR $=6.22,95 \% \mathrm{CI}$ : $1.60-24.15$ ) and to have returned to pre-crash work roles (Adj. $\mathrm{OR}=7.98$, 95\% CI: 1.66-38.42). There were no significant differences in any of these outcomes between the partial and full protection group

\section{Discussion}

This study documents the significant impact of non-fatal motorcycle crashes on the physical, social and emotional well being of riders, including those who were not admitted to hospital. Across all levels of protection there was a significant reduction in participants' physical and mental health at 2 months. For many the recovery progress was slow with less than half of these riders pain free, almost $8 \%$ with some degree of disability and $13 \%$ not having returned to their pre-crash work role six months post-crash. Other studies have noted similar effects for crashed drivers, who continue to report reductions of health 18 months after the crash, highlighting the importance of follow-up services particularly for those not admitted to hospital who may not appreciate the longer term impacts. ${ }^{3}$

We found that whilst all groups experienced significant detriment to their physical and mental health, the impact was greater for unprotected riders (no motorcycle jacket) both in the immediate aftermath of the crash and over the subsequent 6 months. Those with full protection (helmet, motorcycle jacket and pants) tended to fare better generally than either the unprotected or partial protection (helmets and motorcycle jacket) groups, although there were fewer statistically significant differences between partially and fully protected riders on health outcomes. The study definitions would suggest that the better outcomes associated with the full protection group are due to their motorcycle pants. However it is likely that a high proportion of this group also benefited from the motorcycle gloves, boots and body armour they were also wearing, all of which have been associated with significantly reduced injury risk. ${ }^{21}$ The role of body armour may also account for the lack of significant differences between partially and fully protected riders. Whereas a high proportion of both protected groups wore jackets fitted with body armour (82.5\% and $95.7 \%$ ), only $34.0 \%$ of the fully protected riders' motorcycle pants were fitted with body armour. Whereas motorcycle pants without body armour have been associated 
with reduced risk of cut and abrasion injuries, a much stronger benefit was found for those fitted with body armour in reducing the risk of any injuries. ${ }^{21}$

Both protection groups (partial and full) spent less time in hospital and experienced less severe pain, impairment and disability in the two months after the crash. They were also more likely to have fully recovered and returned to their pre-crash work roles within six months. Those with full protection were also less likely to have been admitted to hospital at all or to be receiving medical treatment at six months. Between group differences in the mean and median number of days off-work suggested that the unprotected group lost substantially more work time than the other groups, but the high degree of variability resulted in these differences not being statistically significant.

The reported differences in the degree and duration of physical and mental health consequences for protected and unprotected riders provide strong support for the benefits of protective clothing. The effect remained significant in the regression analysis after adjusting for other risk factors such as the type and force of direct impacts to the body as well as sex, age, occupational group.

It is notable that whilst unprotected riders reported lower scores than the protected groups post-crash, these riders also reported lower scores on the SF-36 mental health domains in the preceding four weeks prior to the crash. Low scores on the mental health domains relate to chronic feelings of fatigue, nervousness and depression and on the extent that emotional problems interfere with social activities and work roles. ${ }^{24}$ The resultant scores in the weeks before the crash are indicative of a pre-existing state of mind or welfare, which in turn might be associated with non-usage of protective clothing. There was no evidence of between-group differences on demographic factors such as age or employment which might have been associated with fewer financial resources. However as the baseline interview was conducted after the crash, we cannot discount the possibility that their responses may have been affected by involvement in the crash itself. Research has however shown the strength of the SF-36 in determining pre-injury health status. ${ }^{35}$

The findings across groups in relation to mental health are consistent with other studies that have identified longer term adverse health outcomes, including ongoing psychological impairment, as a consequence of non-fatal injury crashes in common for all road user groups. ${ }^{3,7,36}$ There have been few studies of the longer term consequences of motorcycle crashes and most have focused on the benefits of helmets. ${ }^{9,26,37-40}$ This study provides evidence of a benefit of motorcycle protective clothing that extends beyond reduction of minor injuries. The findings demonstrate the significant mitigation of longer term physical and psychological consequences of crashes. Whilst injury reduction was most strongly associated with soft tissue injuries, a significant proportion of the disabling consequences of motorcycle crashes have been associated with soft tissue injuries to the limbs. Clarke and Langley found that whilst the majority (82\%) of motorcycle crash compensation claims involved fractures or skeletal impairments, a high proportion (80\%) also suffered disfiguring impairments due to soft tissue injuries including scarring and muscle wasting. ${ }^{41}$ The mental health consequences of disfiguring injuries are also well documented. ${ }^{42,43}$

By re-affirming the protective value of motorcycle clothing, the study also addresses scepticism about its injury reduction capacity which has previously been associated with non-usage. ${ }^{44}$ This is important because the potential value of protective clothing as a safety measure has been discounted in the past on the assumption that it cannot prevent most serious injuries. ${ }^{11}$ Such assumptions are drawn from recognition that motorcycle crashes may involve mechanisms and forces that cannot be mitigated by clothing such as high energy impacts or penetrating, crushing or torsional forces in a crash. ${ }^{12}$ However such crashes are in the minority, motorcycle crash studies from around the world confirm that a high proportion of motorcycle crash injuries are of relatively low severity, particularly when helmets are worn. ${ }^{11,17,20,45-46}$ Whilst protective clothing cannot prevent crashes nor protect riders from high impact forces, the findings of this study suggest that it does reduce the degree of impairment and disability for a substantial proportion of crashed riders.

The results are consistent with earlier reports that injured riders who had been wearing motorcycle clothing, spent less time in hospital, returned to work sooner and had fewer long-term disabilities than did unprotected riders. ${ }^{19}$ The current study investigated the effectiveness of the new generation protective clothing, developed since Schuller's work and since standards were established for motorcycle protective clothing in Europe. ${ }^{20}$ The study also controlled for potentially confounding factors and attempted to reduce selection bias by including riders who had not attended a hospital in order to determine whether protective clothing was associated with non-injury crashes.

The potential for protective clothing to reduce the human costs of motorcycle crashes is substantial. The average cost for all road crashes - across all road user types, in Australia has been estimated as $\$ 266,000$ for hospitalised and $\$ 14,700$ for non-hospitalised injury crashes. ${ }^{47}$ According to the Bureau of Infrastructure Transport and Regional Economics (BITRE) approximately 15\% of those hospitalised will have a degree of disability. Whilst the majority will have mild $(5.0 \%)$ or moderate (5.8\%) limitations, the associated losses per individual for relatively low levels of impairment range from $\$ 125,513$ to $\$ 541,717$.

In countries such as Australia and the US, motorcyclists represent a relatively small proportion of registered vehicles $(4 \%$ and 3\%) with 5000 and 100,000 motorcyclists seriously injured each year respectively. ${ }^{48,49}$ Even within those countries the potential benefits of protective clothing could include an even larger population due to the substantial proportion of relatively minor crashes which are not reported. ${ }^{50,51}$ However there is also great potential in other countries, particularly in Asia, where motorcycles comprise between 40 and $70 \%$ of the vehicle fleet and large increases in traffic crashes are predicted. ${ }^{1,52-53}$

A strength of the study was in the attempt to obtain a representative sample of reported and unreported motorcycle road crashes over twelve months in a defined geographical area. This was designed to avoid the selection bias inherent in earlier crash studies, which included only hospital presentations or police-reported injury crashes, thereby potentially excluding those crashes where protective clothing may have played a role. ${ }^{11,17,54}$

The sample size was a key limitation of the study particularly when stratified by levels of protection. This means that the lack of associations with some outcome factors, such as the disability index, may not necessarily be due to a lack of effect but rather due the lack of statistical power to detect an effect. Conversely, although the analysis was pre-planned, issues of multiplicity inevitably arise due to the presence of several key endpoints. Whilst we cannot completely rule out the possibility of statistically significant but spurious associations, we believe it is important to present these findings for their implications to road safety.

In addition, whilst our retention rate is well within guidelines for a cohort study, ${ }^{55}$ there was systematic bias in the loss to follow-up, with a higher proportion of the unprotected group failing to complete the final surveys. This creates bias in the results although comparisons between the exposure groups found no systematic differences on most of the factors identified as potential confounders of injury severity. The exception was the lower proportion of the full protection group in multi-vehicle 
crashes or with injuries from impact with another vehicle. This may be due to higher rates of single vehicle crashes and higher usage of protective clothing on recreational compared to commuting trips, which has previously been reported. ${ }^{56,57}$ However as there was no evidence of other between-group differences in the proportion with injuries caused by impacts with fixed objects or sliding on the road, nor in the maximum injury severity sustained, the impact of this systematic difference is likely to be minimal.

Another limitation for the analysis was the difficulty of defining a summary measure for protection from the collective contribution of different clothing products. Attempts to construct a single score for protection by summing or weighting all clothing worn proved impractical. This was because few participants wore optimal protection and injuries to any part of the body can be debilitating. Instead, following earlier studies, protection was defined in three incremental levels based on combinations of motorcycle protective jackets and pants. ${ }^{13,18}$ The rationale being jackets are the form of motorcycle protective clothing most commonly worn by riders, whereas motorcycle pants are least likely to be worn and usage could be interpreted as a higher level of protection. ${ }^{11,56}$ The results showed that these levels were useful indicators of increasing levels of protection, and were associated with usage of gloves, boots and body armour. Those classified as unprotected because they did not wear a motorcycle jacket, were also less likely to wear any other protective accessories, whereas the full protection group defined on the basis of wearing a motorcycle jacket and pants, were significantly more likely to also wear all the other protective accessories. The reliance on self report for crash factors was another limitation particularly for estimates of speed however, as was previously reported, the distribution of participants' estimated impact speeds was consistent with that reported in studies where it was objectively assessed. ${ }^{11,21}$

This study provides strong evidence of the benefits of motorcycle protective clothing in reducing the risk and severity of injury and subsequent impairment. However known ergonomic issues particularly relating to heat stress, the lack of global standards and quality control in manufacturing motorcycle protective clothing, justify caution against mandating usage. $^{44,58-60}$

In addition, the differential effect of the partial and full levels of protection requires further examination in a considerably larger cohort. Further work is also required to quantify the protective role of different types of garments to determine the relative contribution of abrasion resistance and impact protection, and to investigate rates of failure under crash conditions. ${ }^{21}$ In addition, work is urgently needed to address factors that have previously been associated with non-usage of protective clothing, most particularly heat stress, in order to encourage increased and viable usage in warm climates.

\section{Conclusions}

This study demonstrates that in addition to reducing the severity of injuries, the benefits of motorcycle protective clothing extend to observable reductions in impairment and disability. Protected riders spent less time in hospital, were less likely to sustain disabilities or to report changes to their physical or mental health, or social functioning and more likely to have returned to their pre-crash work role within six months.

The results provide further evidence to recommend usage of protective clothing by motorcyclists to reduce the risk and mitigate the consequences of injury on their health and well-being. The identified benefits justify further work to resolve issues associated with non-usage including heat stress and product quality.

\section{Role of the funding source}

This study was funded by Swann Insurance Australia. Liz de Rome is supported by an NRMA ACT Road Safety Trust Scholarship. Rebecca Ivers receives fellowship support from the National Health and Medical Research Council of Australia. Narelle Haworth's position is supported by the Motor Accident Insurance Commission of the Queensland State Government. The study sponsors had no involvement in the study design, conduct, analysis and interpretation of the data; writing of the report nor the decision to submit this paper for publication.

\section{Conflict of interest statement}

\section{None.}

\section{Acknowledgement}

We acknowledge and thank research assistants: Judy Perry who managed recruitment and conducted the majority of interviews, Thomas Brandon who developed the data management programme, and David Tesolin who provided independent scoring of participants' injury severity. We also thank the staff at Canberra and Calvary Hospitals and all the motorcycle crash repairers who supported the study. We would particularly like to thank the motorcyclists who took part in the study.

\section{References}

1. Watkins K. The missing link: Road traffic injuries and the Millennium development goals. Make roads safe: the campaign for global road safety. 2010. p. 32, http://www.fiafoundation.org/publications/Documents/the-missing-link.pdf.

2. Mathers C, Boerma T, Ma Fat D. The global burden of disease: 2004 update. Geneva, Switzerland: World Health Organisation; 2008. p. 160, http://www.who.int/ healthinfo/global_burden_disease/GBD_report_2004update_full.pdf.

3. Ameratunga SN, Norton RN, Connor JL, Robinson E, Civil I, Coverdale J, et al. A population-based cohort study of longer-term changes in health of car drivers involved in serious crashes. Annals of Emergency Medicine 2006;48(6):729-36.

4. WHO. Global status report on road safety: time for action Geneva. World Health Organization; 2009 . p. 301, www.who.int/violence_injury_prevention/road_ safety_status/2009.

5. Naumann RB, Dellinger AM, Zaloshnja E, Lawrence BAR, Incidence MT. Total lifetime costs of motor vehicle-related fatal and nonfatal injury by road user type, United States, 2005. Traffic Injury Prevention 2010;11(4):353-60.

6. Johnston P, Brooks C, Savage H. Fatal and serious road crashes involving motorcyclists. Monograph 20 Canberra: Department of Infrastructure; 2008 . p. 26, http:// www.infrastructure.gov.au/roads/safety/publications/2008/mono20.aspx.

7. Mayou R, Bryant B. Consequences of road traffic accidents for different types of road user. Injury 2003;34(3):197-202.

8. Hours M, Bernard M, Charnay P, Chossegros L, Javouhey E, Fort E, et al. Functional outcome after road-crash injury: description of the ESPARR victims cohort and 6-month follow-up results. Accident Analysis and Prevention 2010;42(2):412-21.

9. Crompton JG, Tolulope O, Stevens KA, Efron DT, Haut ER, Haider AH. Motorcycle helmets save lives, but not limbs: a national trauma data bank analysis of functional outcomes after motorcycle crash. Journal of Surgical Research 2009;151(2):1-5.

10. Liu B, Ivers R, Norton R, Boufous S, Blows S, Lo S. Helmets for preventing injury in motorcycle riders (review update). Cockrane Database of Systematic Reviews 2008;(1):37.

11. ACEM. MAIDS in-depth investigation of accidents involving powered two wheelers: final report 1.2. Brussels: Association of European Motorcycle Manufacturers (ACEM); 2004. p. 173, http://www.maids-study.eu/ [accessed 11.10.10].

12. Noordzij P, Forke E, Brendicke R, Chinn B. Integration of needs of moped and motorcycle riders into safety measures. Review and statistical analysis in the framework of the European research project PROMISING, Workpackage 3, report D-2001_5. Leidschendam, The Netherlands: SWOV Institute for Road Safety Research; 2001. p. 212.

13. Hell W, Lob G. Typical injury patterns of motorcyclists in different crash types effectiveness \& improvement of countermeasures. Proceedings of the 37th annual conference of the American Association for the Advancement of Automotive Medicine. San Antonio: AAAM; 1993. p. 77-86.

14. Hurt HH, Ouellet JV, Thom DR. In: University of Southern California Traffic Safety Center, editor. Motorcycle accident cause factors and identification of countermeasures. Technical report. Washington, DC: National Highway Traffic Safety Administration; 1981. 
15. Otte D, Middelhauve V. Quantification of protective effects of special synthetic protectors in clothing for motorcyclists. In: Cesari D, Charpenne A, editors. Proceedings of the international conference of the research council on the biomechanics of impact. Birmingham, UK: IRCOBI; 1987. p. 1-18.

16. Aldman B, Cacciola I, Gustafsson H, Nygren A, Wersall J. The protective effect of different kinds of protective clothing worn by motorcyclists. In: Charpenne JPC, editor. Proceedings of the 6th international conference of the research council on the biomechanics of impact. Salon-de-Provence, France: IRCOBI; 1981. p. 1-9.

17. Hurt HH, Ouellet J, Wagar I. Effectiveness of motorcycle safety helmets and protective clothing. Proceedings of the 25th annual conference of the American Association for the Advancement of Automotive Medicine. San Francisco: AAAM; 1981. p. 223-35.

18. Schuller E, Beier G, Spann W. Effectiveness of protective clothing in Munich area motorcycle accidents. Proceedings of the 26th Stapp car crash conference. 1982:259-67.

19. Schuller E, Beir G, Spann W. Disability and impairment of protected and unprotected motorcycle riders. SAE international congress and exposition - crash injury impairment and disability: long term effects. Warrendale, PA: The Engineering Society for Advancing Mobility Land Sea Air and Space (SAE); 198.6p. 51-6.

20. EEVC. Report on motorcycle safety. An EEVC paper, report of the Ad-hoc Group on Motorcycle Safety, 1993. Brussels: European Experimental Vehicles Committee; 1993. p. 75.

21. de Rome L, Ivers R, Fitzharris M, Du W, Richardson D, Haworth N, et al Motorcycle protective clothing: protection from injury or just the weather? Accident Analysis and Prevention 2011;43(6):1893-900.

22. Teasdale G, Jennett B. Assessment of coma and impaired consciousness: a practical scale. The Lancet 1974;2(42):81-4.

23. AAAM. In: Gennarelli TA, Wodzin E, editors. Abbreviated injury scale 2005. Barrington, IL, USA: Association for the Advancement of Automotive Medicine (AAAM); 2005.

24. Ware J. SF-36 health survey update. Spine 2000;25. p. 30-31.

25. Wolfe F, Michaud K, Pincus T. Development and validation of the health assessment questionnaire ii a revised version of the health assessment questionnaire. Arthritis \& Rheumatism 2004;50(10):3296-305.

26. Fitzharris M, Fildes B, Charlton J, Kossmann T. General health status and functional disability following injury in traffic crashes. Traffic Injury Prevention 2007;8(3):309-20.

27. Scott J, Huskisson EC. Graphic representation of pain. Pain 1976;2:175-84.

28. Fitzharris M, Bowman D, Ludlow K. Factors associated with return-to-work and health outcomes among survivors of road crashes in Victoria. Australian and New Zealand Journal of Public Health 2010;34(2):153-60.

29. Lin MR, Chang SH, Huang W, Hwang HF, Pai L. Factors associated with severity of motorcycle injuries among young adult riders. Annals of Emergency Medicine 2003;41(6):783-91.

30. Pai CW, Saleh W. Exploring motorcyclist injury severity resulting from various crash configurations at T-junctions in the United Kingdom - an application of the ordered probit models. Traffic Injury Prevention 2007;8(1):62-8.

31. Zambon F, Hasselberg M. Factors affecting the severity of injuries among young motorcyclists - a Swedish Nationwide Cohort Study. Traffic Injury Prevention 2006;7(2):143-9.

32. ATSB. Motorcycle rider age and risk of fatal injury. Motorcycle safety monograph 12 , Canberra: Australian Transport Safety Bureau; 2002 http://www.infrastructure. gov.au/roads/safety/publications/2002/Mcycle_Age_1.aspx.

33. ABS. ANZSCO - Australian and New Zealand Standard Classification of Occupations. Catelogue no: 1220.0. 1st ed. Canberra: Australian Bureau of Statistics; 2009.

34. ABS. National Health Survey: SF-36 population norms Australia. Canberra: Australian Bureau of Statistics|; 1997.

35. Watson WL, Ozanne-Smith J, Richardson J. Retrospective baseline measurement of self-reported health status and health-related quality of life versus population norms in the evaluation of post-injury losses. Injury Prevention 2007;13(1):45-50.

36. Airey C, Chell S, Rigby A, Tennant A, Connelly J. The epidemiology of disability and occupation handicap resulting from major traumatic injury. Disability and Rehabilitation 2001;23(12):509-15.

37. Bull JP. Disabilities caused by road traffic accidents and their relation to severity scores. Accident Analysis and Prevention 1985;17(5):387-97.
38. Ferrando J, Plasencia A, MacKenzie E, Oros M, Arribas P, Borrell C. Disabilities resulting from traffic injuries in Barcelona, Spain: 1-year incidence by age, gender and type of user. Accident Analysis and Prevention 1998;30(6): 723-30.

39. de Oliveira NL, de Sousa RM. Injury diagnosis quality of life among motorcyclists, victims of traffic accidents. Revista Latino-Americana de Enfermagem 2003;11(6):749-56.

40. Hotz G, Cohn S, Mishkin D, Castelblanco A, Li P, Popkin C, et al. Outcome of motorcycle riders at one year post-injury. Traffic Injury Prevention 2004;5(1): 87-9.

41. Clarke JA, Langley JD. Disablement resulting from motorcycle crashes. Disability and Rehabilitation 1995;17(7):377-85.

42. Spevak C, Buckenmaier III C. Catastrophizing and pain in military personnel. Current Pain and Headache Reports 2011:1-5.

43. States JD, Viano DC. Injury impairment and disability scales to assess the permanent consequences of trauma. Accident Analysis and Prevention 1990;22(2):151-9.

44. de Rome L, Ivers R, Haworth N, Heritier S, Du W, Fitzharris M. Novice riders and the predictors of riding without motorcycle protective clothing. Accident Analysis and Prevention 2011;43(3):1095-103.

45. Otte D, Willeke H, Chinn B, Doyle D, Schuller E. Impact mechanisms of helmet protected heads in motorcycle accidents - accidental study of COST 327. Safety environment future: proceedings of the 1998 international motorcycle conference. Munich: Institute fur Zweiradsicherheit; 1998. p. 83-109.

46. Haworth N, Smith G, Brumen I, Pronk N. Case-control study of motorcycle crashes. CR 174. Canberra, ACT: Federal Office of Road Safety; 1997. p. 88.

47. BITRE. Cost of road crashes in Australia 2006. Report 118. Canberra, Australia: Bureau of Infrastructure Transport and Regional Economics; 2009. http://www.bitre. gov.au/publications/48/Files/Cost_of_road_crashes_in_Australia.pdf.

48. AIHW. Serious injury due to land transport accidents, Australia 2006-07. Injury research and statistics series no. 53. Canberra: Australian Institute of Health and Welfare; 2009.

49. NHTSA. Motorcycles: Traffic safety facts 2008 data. Washington, DC: National Highway Transport Safety Administration; 2008.

50. Lin MR, Kraus JF. Methodological issues in motorcycle injury epidemiology. Accident Analysis and Prevention 2008;40(5):1653-60.

51. Richardson DB, Paini C. Amalgamation of police and hospital trauma data in the Australian Capital Territory 2002-2003. Road safety research, education and policing conference. 2006. www.rsconference.com.

52. WHO. In: Peden M, Scurfield R, Sleet D, Mohan D, Hyder A, Jarawan E, et al. editors. World report on road traffic injury prevention. Geneva: World Health Organisation; 2004.

53. Kopits E, Cropper M. Traffic fatalities and economic growth. Accident Analysis and Prevention 2005;37(1):169-78.

54. Clarke DD, Ward P, Bartle C, Truman W. In-depth study of motorcycle accidents. Road Safety Research Report No. 54. London: Department for Transport; 2004. p. 67.

55. Kristman V, Manno M, Côté P. Loss to follow-up in cohort studies: how much is too much? European Journal of Epidemiology 2004;19(8):751-60.

56. de Rome L. The injury reduction benefits of motorcycle protective clothing. NTSB Public Forum on Motorcycle Safety, September 12-13 2006. Washington, DC: National Transport Safety Board; 2006 http://www.ntsb.gov/events/symp_motorcycle_ safety/symp_motorcycle_safety.htm.

57. Wishart D, Watson B, Rowden P. Motorcycle rider protective apparel wearing: observational study results from the Brisbane and Canberra Regions. Journal of the Australasian College of Road Safety 2009;20(4):52-9.

58. Robertson S, Porter J. Motorcycle ergonomics: an exploratory study. Contemporary ergonomics: proceedings of the ergonomics society's annual conference. 1987:173-8.

59. Noordzij PC, Vis AA. Safety of motorcycling in the Netherlands. Safety environment future: proceedings of the 1998 international motorcycle conference. Munich: Institute for Motorcycle Safety; 1998. p. 125-32.

60. Manzardo D. Report on the Performance of Riders Protective Devices and the corresponding injuries of riders. State-of-the-art regarding motorcyclists helmets and clothing. Future research guidelines. APROSYS SP44 integrated project on advanced protection systems. 2006. http://www.aprosys.com/ [accessed 20.08.10]. 